\title{
Axial Crushes Simulation of Double Thin-Walled Metallic Structure Inserted with Polymeric Foam
}

\author{
A. Othman and Azrol Jailani, Member, IACSIT
}

\begin{abstract}
The paper deal with numerical studies of dynamic axial loading of thin-walled metallic titanium alloy extrusion double cell polyurethane foam-filled square. Nonlinear dynamic simulations were performed on empty as well on foam-filled modeling. The dynamics non-linear finite element code ABAQUS standard and explicit were used to simulate the buckling and crushing of columns. The influence of filler material on energy absorption and behavior of double cell thin-walled square metallic titanium alloy extrusion were examined. Three main collapse modes were identified for the crushed model, such as compound diamond asymmetric, concertina axisymmetric and mixed mode fold formations. Three different arrangement of double-cell inner column were examined and investigated. Filling the polyurethane foams into tubular double cell played important factor positively influencing the energy absorption capability. Results showed that the tubular energy absorption capability was affected significantly by varying of velocity impact and wall-thickness as well as arrangement inner tube cross-section.
\end{abstract}

Index Terms-Finite element modeling, double cell, axial loading, energy absorption, foam filled.

\section{INTRODUCTION}

A vehicle crashworthy structure has been developed by engineers and researchers around the world from two decades until now as a purpose to improve vehicle safety during collision event [1]-[8]. During the progressive collapse of crashworthy structures it has an ability to protect the occupants from severe injury in collision accidents, including side impacts with other vehicles and roadside objects [1]. Side collisions are among the most dangerous car accidents [2]. While in frontal and rear-end collision the occupant can be well protected by deformation elements (crash boxes) placed outside the occupant cell, there is no room for such crush zones in body's side [3]. For this reason the side body of the car and the structural frame must be designed in order to avoid excessive deformation. Strength and stiffness, however, are not the only requirements for improving resistance to side impacts: provided a sufficient amount of kinetic energy, absorbed in an impulsive way by the impacted vehicle, even the stiffer structure will plastically deform to a certain amount [4]-[7]. Therefore, side structures must also absorb a large amount of plastic deformation energy and, unlike axial absorbers, find a compromise between the minimization of the maximum transmitted load and the

Manuscript received May 15, 2013; revised July 10, 2013.

A. Othman is with the Mechanical Engineering Department, Polytechnic Port Dickson, KM. 14 Jalan Pantai, 71050, Si Rusa, Port Dickson, Negeri Sembilan, Malaysia (e-mail: akbar.othman@gmail.com).

Azrol Jailani is with The Association of Ledang Community Youth, 152 Jalan Puteri 1/6, Bandar Baru Tangkak, 84900 Tangkak, Johor (e-mail: azrol.jailani@yahoo.com). maximization of the deformation. There are several remedies and design criteria which can be followed if the goal is to increase the crash resistance to a lateral impact, such as strengthening the rocker section and the floor pan (e.g. with high-strength steels, internal baffles and rigid foam fillings), to help transfer [6]. In this study, Fig. 1 and Table I illustrated and showed finite element model and dimension of various cross-section tubes including type of arrangement of double cell. The objective in this study were to determine and investigate the dynamic energy absorption of various cross-section of polyurethane foam filled titanium alloy under axial loading using finite element commercial software's of ABAQUS [8]. In this study also were carried out the variable of velocity dynamic loading and wall-thickness in order to identify the influence of crashworthiness characteristics.

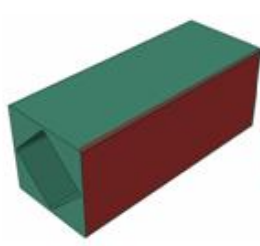

TYPE A

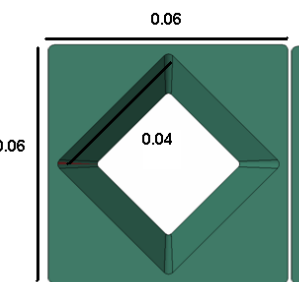

TYPE A

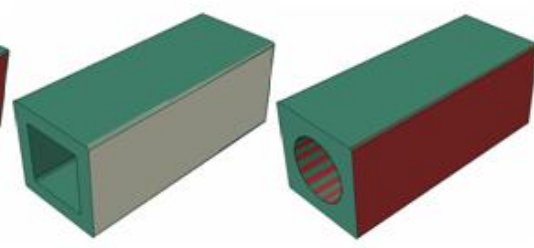

TYPE C

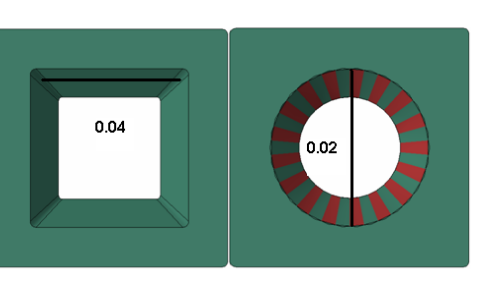

TYPE B

TYPE C

Fig. 1. Finite element model of double cell.

TABLE I: Dimension of Finite Element Model of Double CELL

\begin{tabular}{|c|c|c|c|c|c|c|}
\hline 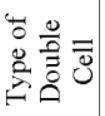 & 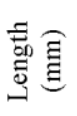 & 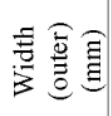 & 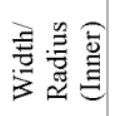 & $\begin{array}{l}\frac{2}{0} \\
\frac{0}{0} \\
>\end{array}$ & 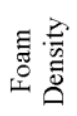 & $\underset{\Xi}{\stackrel{d}{\Xi}} \underset{\Xi}{\Xi}$ \\
\hline A & 150 & $60 \times 60$ & $40 \times 40$ & 10,20 & 100 & $1.0,1.52 .0$ \\
\hline B & 150 & $60 \times 60$ & $40 \times 40$ & 10,20 & 100 & $1.0,1.52 .0$ \\
\hline $\mathrm{C}$ & 150 & $60 \times 60$ & 20 & 10,20 & 100 & $1.0,1.52 .0$ \\
\hline
\end{tabular}

\section{FinITE ELEMENT ModELING}

To represent real progressive collapse events, the velocity and time need to be suitable. Taking $\mathrm{a}=196.2 \mathrm{~m} / \mathrm{s} 2$ as the benchmark since humans can only sustain $20 \mathrm{~g}$ of acceleration, value of sufficient crushing time can be obtained. The initial velocity (V) of the tube is set to be $6 \mathrm{~m} / \mathrm{s}$, 
hence calculated value for crushing time; $(\mathrm{t})$ was found to be $0.02 \mathrm{~s}$. The other important parameter of representing crushing event is boundary condition. In structural analyses, boundary conditions are applied to those regions of the model where there displacements or rotations are known. Such regions may be constrained to remain fixed or may have specified nonzero displacements or rotations. In this model the ENCASTRE $(\mathrm{V} 1=\mathrm{V} 2=\mathrm{V} 3=\mathrm{VR} 1=\mathrm{VR} 2=\mathrm{VR} 3=0)$ condition has been used where the top section of the tube is constrained completely and thus, cannot move in any direction also.

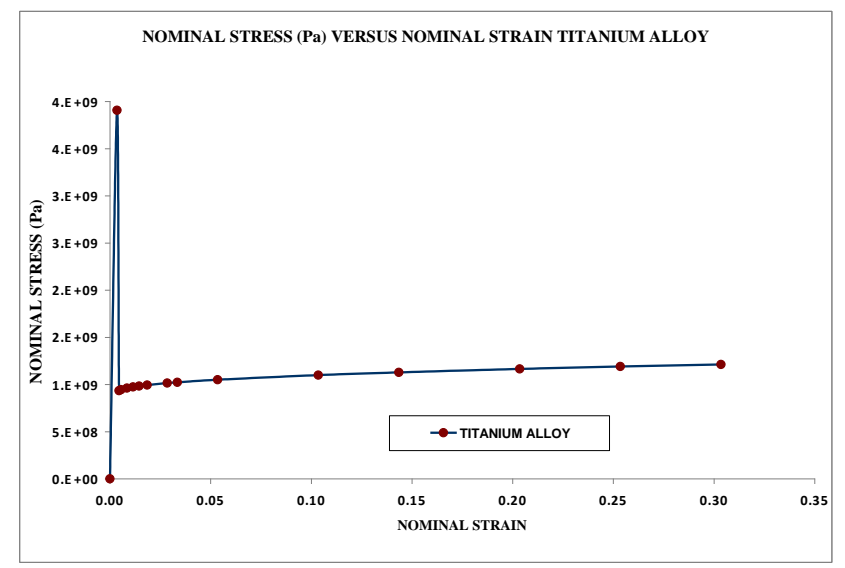

Fig. 2. Nominal stress -strain curve of titanium alloy.

POLYURETHANE FOAM STRESS-STRAIN CURVES UNDER UNIAXIAL COMPRESSIVE LOADING

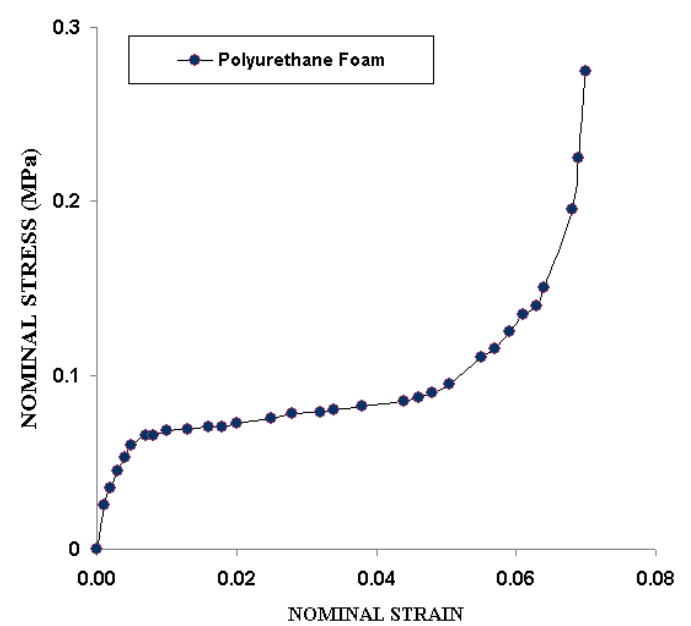

Fig. 3. Nominal stress -strain curve of polyurethane foam.

The bottom section, however, is fixed in the horizontal direction but is free to move in vertical direction $(\mathrm{V} 1=\mathrm{V} 2=$ VR1 = VR2 = VR3 =0). The direction in which motion is possible is called degree of freedom (dof), hence this model only has a single degree of freedom. A mechanical, concentrated force with a magnitude of $500 \mathrm{~N}$ was applied in order to initiate the crushing process. The actual load magnitude is not critical because ABAQUS [8] will report buckling loads as a fraction of the applied load.The total work done (W) during the axial crushing of the cones are equal to the area under the load/displacement curve and is evaluated as:

$$
W=\int P d s
$$

where, $P$ is the force acting on the tube. Therefore the specific energy absorption per unit mass, $E$ is recognized as:

$$
E=\frac{W}{m}
$$

where, $m$ is the crushed mass of the thin-walled tube.

\section{MATERIAL MODEL AND PROPERTIES}

Three types of models were analyzed in this study which is type $\mathrm{A}, \mathrm{B}$ and $\mathrm{C}$ with different arrangement of inner tube profile and filling the foam between space of inner and outer of tube profiles. Material of titanium alloy was used to determine the crushing behavior and having of $60 \times 60 \mathrm{~mm}$ outer diameter arrangement with inner tube were $40 \times 40,40$ $\times 40 \mathrm{~mm}$, radius of rounded tube profile of $20 \mathrm{~mm}$. the wall-thickness of 1.0 , and $2.0 \mathrm{~mm}$ were examined and investigated. The foam-filled models were carried out from two tubes having outer wall from the same material as empty tube profiles as well as inner wall of tube. The inner tube has varied with three different arrangements including 40 x 40 and rounded at $30 \mathrm{~mm}$ radius and 1.0 and $2.0 \mathrm{~mm}$ wall-thickness but constrained at the same thickness as well as outer tube thickness. All sections had a length of $150 \mathrm{~mm}$. The empty tube sections were tested as foam-filled tube profiles only with the foam in between inner and outer tube wall. Fig. 2 and Fig. 3 illustrates typical test model geometry. In this study the velocity dynamic of impact was applied at 10 and $20 \mathrm{~m} / \mathrm{s}$ axially onto the frontal crash flat plate analytical rigid surface. The simulation, which normally is run as a background process, is a stage in which ABAQUS/Explicit [8] solves the numerical problem defined in the model. ABAQUS/Explicit is a special-purpose analysis product that uses an explicit dynamic finite element formulation. It is suitable for short, transient dynamic events, such as impact and blast problems, and is also very efficient for highly nonlinear problems involving changing contact conditions, such as forming simulation. The evaluation is generally done interactively using the visualization module of ABAQUS/CAE [8]. The visualization module, which reads the neutral binary output database file, has a variety of options for displaying the results, including color contour plots, animations, deformed shaped plots, and $\mathrm{X}-\mathrm{Y}$ plots.

\section{RESUlT AND DISCUSSION}

All square foam-filled tubes profiles of this analysis test series having a foam density than the square ones rather showed local progressive damage, but not typically progressive, deformation behavior, where the formation of folds began at different locations, generally not in a sequential manner. Furthermore, these element models buckled extensionally with all folds moving outwards, which is obviously caused by the presence of the foam core. The extensional deformations are also evident from the dynamic load compression displacement curves in Fig. 4 to 5, because the load fluctuations are much more pronounced. Filling polystyrene foam inside of the tubes was in general accompanied by shorter wavelengths of the individual folds which is holds true for all element model test series. Within element model test series empty and foam-filled square tubes, which were arranged in different ways, empty, foam-filled 
tubes, and arrangement with dimension of inner square tube profile, were analyzed.
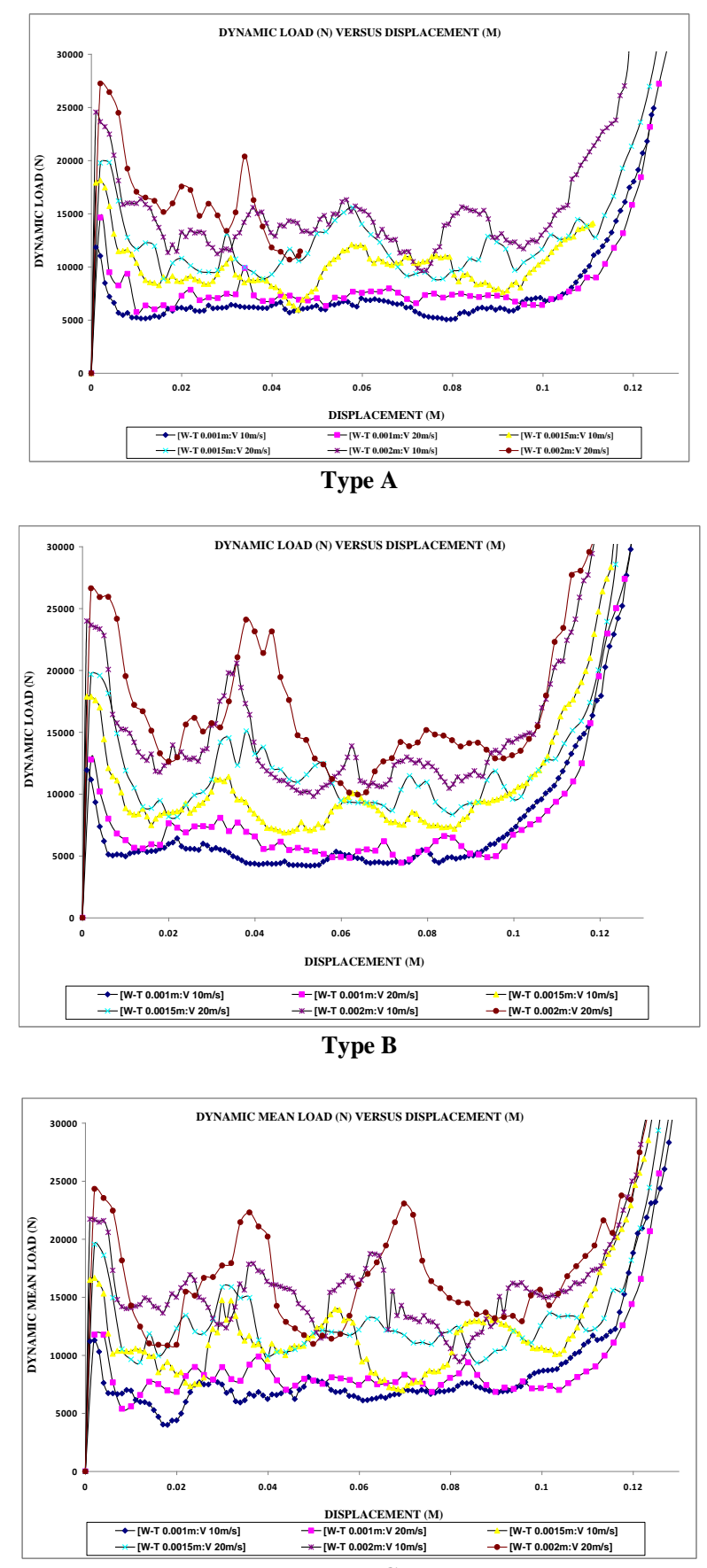

Type C

Fig. 4. Dynamic (N) versus displacement (m) tubular of foam-filled profile.

The inner material profile in Fig. 6 which is $50 \times 50 \mathrm{~mm}$ was used inside the outer square filling with polystyrene foam with $100 \mathrm{~kg} / \mathrm{m}^{3}$ density. The typical progressive buckling characteristics, which could be observed in most numerical analysis of this test series of wall thickness 1 and 2 $\mathrm{mm}$ as well as variable dynamic impact loading of 10 and 20 $\mathrm{m} / \mathrm{s}$, are evident from the deformed elements shown in Fig. 6 . The type of A, B and C foam-filled tube square profile also reveals the higher densification in the outer region of the foam core due to a multiaxial state of compression illustrated resulting from foundation effects of the foam with respect to the profile. Global failure was observed only for the foam-filled tube foam filled elements. This can be traced back to global buckling of the slender inner profiles, leading to overall buckling of the whole arrangements. All filled element modeling that deformed locally began to buckle in an extensional mode, but after the formation of some folds most switched to an inextensional mode. The measured dynamic loads versus displacement curves from Fig. 6 also clearly display the effects of the change of deformation modes. The foam-filled tube element model show a pronounced load fluctuation during the load cycles, owing to the extensional folding modes, which is followed by minor differences between maximum and minimum loads due to the inextensional buckling deformations of the extruded titanium alloy tubes.

The gluing between filler and tubes of element model obviously caused the lobes to be filled with polystyrene foam for the most part almost of wall-thickness 1 and $2 \mathrm{~mm}$ square tube. However, some breaking of the interface can also be observed for these element models. It should be noted, however, that the main reason for applying fiction coefficient for these interaction surface of inner, outer and foam element geometries model. Furthermore, the dynamic load versus displacement curves reveal a distinct quasi-steady progress of the crushing forces which is fluctuating around a more or less constant value, provided that the average foam density is not too high. The ascending slope of the force level of double cell type of B seen in Fig. 6 which square inner profile of 40 x 40 $\mathrm{mm}$, however, is due to the foam behavior itself. The stress-strain curves of uniaxially compressed foam cores shown in Fig. 6, indicate that for foams of largest volume and maintain low densities no marked plateau region can be characterized by more or less constant stresses, but rather a region of constantly increasing stresses can be observed thus corresponding with the measured dynamic load versus displacement compression behavior of crush elements model filled with foams of higher volumes. Fig. 6 showed that the double cell type of $\mathrm{C}$ of the sectioned inner square tube of 30 $\times 30$ profile. Noted that element model was crushed far beyond the stroke length. Whereas the square inner and outer element model rather tended to buckle inextensionally, a typical extensional folding mode is apparent from the square both of inner and outer crush elements of this test series.



Fig. 5. Dynamic absorbed energy (Joule) type of double cell type of A, B and $\mathrm{C}$ foam-filled profile [Wall-Thickness $=1.0,1.5$ and $2.0 \mathrm{~mm}$ ] (Velocity $=10$ and $20 \mathrm{~m} / \mathrm{s}$ ).

\section{CONCLUSION}

The test element results model presented here confirm that the mass related mean load level may considerably be 
improved by filling tubular members with polystyrene foam. Provided that the plastic buckling behavior remains characterized by local modes, essential enhancements were obtained for all investigated shapes and dimensions. These improvements may partly be traced back to the axial compression of the foam cores themselves, but interaction efficiency is also play a substantial role that the simple estimates. With respect to the total energy absorption capacity of a given crush element, however, improvements are less pronounced. The reason for this is that the maximal crushing distances, which may be utilized for energy dissipation, reduce with increasing foam densities. Nevertheless, improvements of the mass the investigation of foam-filled tube arrangements revealed that these may be preferable to empty analysis. It could be shown that improvements are mainly due to the presence of the inner profiles, which are in general more mass efficient than the outer ones. Interaction effects are somewhat less pronounced that for empty tubes. An analysis of interaction effects was performed, which not only allowed to determine the relative $\mathrm{c}$ influences of such effects onto the mean load levels but also to and some explanations concerning the differences between cross-sectional shapes and mono-and foam-filled tube arrangements, respectively.

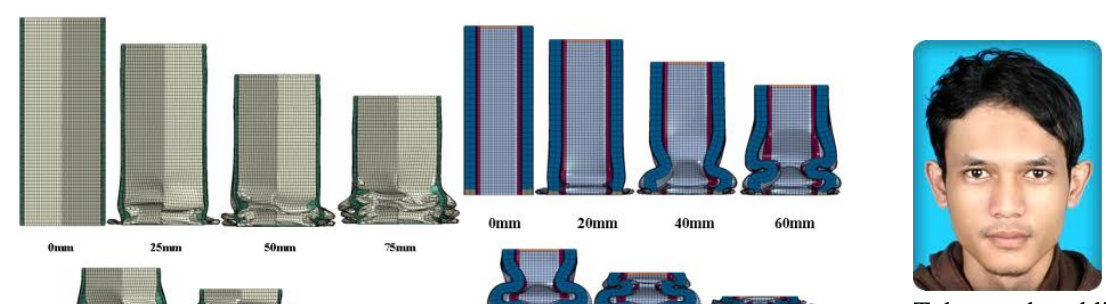

Akbar Othman is a lecturer of Mechanical Engineering at Port Dickson Polythecnic. He received his first degree in Mechanical Engineering from Universiti Tun Hussien Onn Malaysia in 2006, then he continued studies at Universiti Putra Malaysia (UPM) in Structure and Design Engineering, leading to Master degree. $\mathrm{He}$ is working on simulating crushing performance of hybrid laminated material Tapered Tubes under oblique loading conditions. He was awarded with a M. Sc. degree in 2009. After that, his has been pursuing his Ph.D degree in Quasi-Static and Energy Absorption Performance of Foam-Filled Composite Tubes under Off-axis Loading at Universiti Kebangsaan Malaysia, (UKM) in progress. This author became a member (M) of IAENG, International Association of Computer Science and Information Technology (IACSIT) and board of Engineer Malaysia (BEM).

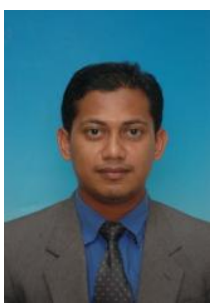

Azrol Jailani is a member of IAENG (121660) and he was born in Johor, Malaysia on $5^{\text {th }}$ February. He got a first degree in Mechanical Engineering with honors from Universiti Tun Hussein Onn Malaysia in 2007. $\mathrm{He}$ is currently pursuing studies in the same field in postgraduate program at Universiti Tun Hussein Onn Malaysia.

$\mathrm{He}$ is currrently an independent researcher at the association of Ledang Community Youth, Johor, Malaysia. Previously he had served in Ledang Community College and Port Dickson Polytechnics, Malaysia as a lecturer. $\mathrm{He}$ is interested in the field of materials science and many research he has published into international journal.

Engr. Jailani is member of Institute of Engineers, Malaysia (28618), Board of Engineers Malaysia (53480A), International Association Computer Science \& Information Technology (80344528) and Institute of Materials Malaysia (4109). Paper "Progressive Damage of Double-Cell Square Aluminium 6061-T5 Alloy Polystyrene Foam-Filled Section" gets the best paper awards at 2nd. International Conference on Arts, Social Sciences \& Technology (iCAST2012), 3rd. - 5th. March 2012, Penang, Malaysia. 